\title{
COST RECOVERY RATE PROGRAM JAMINAN KESEHATAN NASIONAL BPJS KESEHATAN
}

\author{
Sandra Aulia \\ Supriadi \\ Dewi Kartika Sari \\ Arthaingan Mutiha \\ Program Vokasi Universitas Indonesia
}

\begin{abstract}
Program Jaminan Kesehatan Nasional (JKN) is an Indonesian public health care program organized by Badan Penyelenggara Jaminan Sosial (BPJS). The health care system in this tiered program, all patients are served on the first level health facility and can be referred to more advanced facilities. Payments made by the advanced health care facility uses INA CBG's rates. Many parties complaint against the INA CBG's rates that are considered detrimental to the hospital. This study aims to determine whether the INA CBG's rates is profitable by look at cost recovery rate of the tariffs. This study analyzes INA CBGs rates set by the government uses the real costs incurred hospital. The data collected in this study are primary data and secondary data. This study found that the cost recovery rate is 93\% means that hospitals gain $7 \%$ by using INA CBG's rates.
\end{abstract}

Keywords: BPJS, JKN, cost recovery, revenues, costs, profits

\begin{abstract}
ABSTRAK: Program Jaminan Kesehatan Nasional (JKN) merupakan program pemeliharaan kesehatan masyarakat Indonesia yang diselenggarakan oleh Badan Penyelenggara Jaminan Sosial (BPJS). Sistem pelayanan kesehatan pada program ini berjenjang, semua pasien dilayani pada fasilitas kesehatan tingkat pertama dan dapat dirujuk ke fasilitas tingkat lanjut. Pembayaran pelayanan kesehatan yang dilakukan oleh fasilitas tingkat lanjut menggunakan tarif INA CBG's. Banyak keluhan terhadap tarif INA CBG's yang dianggap merugikan rumah sakit. Penelitian ini bertujuan mengetahui apakah tarif INA CBG's menguntungkan dengan melihat cost recovery rate dari tarif tersebut. Penelitian ini menganalisis tarif INA CBGs yang ditetapkan pemerintah menggunakan biaya riil yang dikeluarkan rumah sakit. Data yang dikumpulkan dalam penelitian ini merupakan data primer dan data sekunder. Penelitian ini menemukan bahwa cost recovery rate sebesar 93\% artinya rumah sakit memperoleh keuntungan $7 \%$ dengan menggunakan tarif INA CBG's.
\end{abstract}

Kata kunci: BPJS, JKN, cost recovery, pendapatan, biaya, keuntungan

\footnotetext{
${ }^{1}$ Draft pertama: 10 Desember 2014; Revisi: 12 Januari 2015; Diterima: 5 Februari 2015

Penulis dapat dikontak melalui: salia@zahoo.com
} 


\section{PENDAHULUAN}

Program Jaminan Kesehatan Nasional (JKN) diluncurkan oleh Presiden Susilo Bambang Yudhoyono pada tanggal 1 Januari 2014. JKN ini adalah jaminan berupa perlindungan kesehatan agar peserta memperoleh manfaat pemeliharaan kesehatan dan perlindungan dalam memenuhi kebutuhan dasar kesehatan yang diberikan kepada setiap orang yang telah membayar iuran atau iurannya dibayar oleh pemerintah. Program ini diselenggarakan oleh Badan Penyelenggara Jaminan Sosial (BPJS) Kesehatan, yang merupakan perubahan dari PT ASKES.

Berdasarkan peraturan BPJS tahun 2014, peserta JKN dapat dilayani di fasilitas kesehatan yang ada di Indonesia dengan sistem berjenjang, yaitu mulai dari fasilitas kesehatan tingkat pertama sampai fasilitas tingkat lanjutan. Fasilitas kesehatan ini bisa milik pemerintah, pemerintah daerah dan milik swasta yang memenuhi ketentuan BPJS dan bekerjasama dengan BPJS. Fasilitas kesehatan tingkat pertama antara lain; Puskesmas, Praktek Dokter, Praktek Dokter Gigi, Klinik Pratama dan Rumah Sakit Tipe D. Sedangkan fasilitas tingkat lanjutan yaitu; Klinik Utama, Rumah Sakit Umum dan Rumah Sakit Khusus.

Berdasarkan peraturan BPJS Tahun 2014, pembayaran pelayanan kesehatan oleh BPJS ke fasilitas tingkat lanjut dengan menggunakan tarif INA CBG's. Tarif paket INA CBG's adalah sistem pembayaran berdasarkan diagnosa. Dalam pembayaran menggunakan sistem INA CBGs, baik Rumah Sakit maupun pihak pembayar tidak lagi merinci tagihan berdasarkan rincian pelayanan yang diberikan, melainkan hanya dengan menyampaikan diagnosis keluar pasien dan kode DRG (Disease Related Group). Besarnya penggantian biaya untuk diagnosis tersebut telah disepakati bersama antara provider/asuransi atau ditetapkan oleh pemerintah sebelumnya. Perkiraan waktu lama perawatan (length of stay) yang akan dijalani oleh pasien juga sudah diperkirakan sebelumnya disesuaikan dengan jenis diagnosis maupun kasus penyakitnya.

Sistem pembayaran dengan tarif paket INA CBG's pada program JKN ini dirasakan merugikan rumah sakit. Ketua Umum Pengurus Besar (PB) Ikatan Dokter Indonesia (IDI) Zainal Abidin mengatakan, sebelumnya memang RS swasta sudah melakukan prediksi dalam pelaksanaan JKN banyak kerugian yang didapatkan (Sindo, 2014). Oleh sebab itu, Tim Nasional Casemix Center (NCC) Kementerian Kesehatan (Kemkes) melakukan revisi terhadap sistem pembayaran tarif Indonesia Case Based Group.

Penelitian ini menjadi penting karena penelitian ini menganalisa tarif INA CBGs yang ditetapkan pemerintah terhadap biaya riil yang dikeluarkan oleh rumah sakit. Data yang digunakan menggunakan data primer atas biaya langsung dan biaya tidak langsung yang secara nyata dikeluarkan oleh rumah sakit. Penelitian sebelumnya sebagian besar menggunakan analisa dari data laporan keuangan tahunan yang dikeluarkan oleh rumah sakit serta lingkup penelitian lebih banyak untuk rumah sakit pemerintah, sedangkan penelitian ini menganalisis cost recovery untuk rumah sakit swasta.

Perubahan tarif INA CBG's dapat menyebabkan keuntungan dan kerugian bagi rumah sakit. Sebagian orang berpendapat, tarif INA CBG's memberikan kerugian bagi rumah sakit, sehingga penelitian ini ingin menganalisis tingkat pemulihan biaya (cost recovery rate) yang dikeluarkan oleh rumah sakit dalam melayani pasien JKN untuk pelayanan pasien rawat jalan, sehingga akan terlihat apakah tarif INA CBG's tersebut menguntungkan atau merugikan rumah sakit. 


\section{KERANGKA TEORITIS DAN PENGEMBAGNAN HIPOTESIS}

Rumah sakit diwajibkan oleh pemerintah untuk menyediakan sebagian pelayanannya bagi masyarakat miskin, namun rumah sakit diharapkan dapat bertahan hidup dan menjaga kesehatan organisasi dengan mengupayakan keuntungan, atau tercapainya impas biaya (cost recovery) Impas biaya tercapai jika biaya pengeluaran total (total cost) dapat ditutup (recovery) oleh total pendapatan (total revenue) dari pelayanan yang diselenggarakan tersebut.

\section{Jaminan Kesehatan Nasional (Jamkesnas)}

Menurut UU No.4 tahun 2004 tentang Sistem Jaminan Sosial Nasional (SJSN) elemen pembiayaan kesehatan harus melekat pada penyediaan pelayanan kesehatan. Berdasarkan penelitian Sreshthaputra (2001) dan WHO (2005) sistem pengelolaan asuransi kesehatan sosial secara nasional perlu dianalisis berdasarkan kriteria keadilan, efisiensi, dan daya tanggap (responsiveness), baik dalam aspek pembiayaan maupun penyediaan pelayanan kesehatan.

Pembiayaan Jamkesmas atas biaya klaim yangberdasarkan pada Indonesia Case Based Groups (INA-CBG's) disusun berdasarkan pada "clinical pathway" dimana definisi Clinical Pathway menurut Queensla Health Clinical Pathway Boards 2002 adalah rencana penatalaksanaan pasien bersifat multidisiplin yang telah memiliki detail langkah-langkah mulai pasien masuk hingga keluar rumah sakit. Biaya Kelompok Diagnosis Terkait (Cost Of Diagnosis Related Groups/Cost of DRG) adalah keseluruhan biaya yang dikeluarkan mulai pasien masuk pendaftaran, diagnosis, terapi dan pulang yang terangkum dalam alur integrated clinical pathway.

UU No.24 tahun 2011 tentang Badan Penyelenggara Jaminan Sosial (BPJS) yang telah diberlakukan mulai Januari 2014 menerapkan sistem pembayaran INA-CBGs yang berlaku untuk semua jenis penyakit. Hal ini sejalan dengan penerapan jaminan kesehatan untuk seluruh rakyat (universal coverage) beban biaya pengobatan penyakit termasuk penyakit katastropik menurut Thabrany (2011).

\section{Asuransi Kesehatan Universal (Universal Health Insurance)}

Program Jamkesnas merupakan salah satu bentuk sistem asuransi kesehatan universal, dimana biaya kesehatan warga negara ditanggung oleh pemerintah. Penelitian terkait sistem asuransi universal telah banyak dilakukan di berbagai negara. Sebagai contoh penelitian yang dilakukan oleh Chang, Chang, Das, dan Li (2004), Ernst dan Szczesny (2005), Lehtonen (2007), dan Hung dan Chang (2008).

Chang, Chand, Das, dan Li (2004) dan Hung dan Chang (2008) telah melakukan penelitian mengenai efek dari asuransi kesehatan nasional dengan studi kasus di Taiwan. Chang, Chand, Das, dan Li (2004) meneliti bagaimana pengaruh regulasi kesehatan (national health insurance - NHI) terhadap efisiensi operasional Rumah Sakit di Taiwan. Sedangkan Hung dan Chang (2008) melakukan penelitian yang bertujuan untuk mengetahui faktor-faktor apa saja yang berpengaruh langsung terhadap peningkatan biaya setelah adanya NHI. Dengan menggunakan data survey rumah sakit tahunan yang dikompilasi oleh departemen kesehatan Taiwan mulai dari tahun 1994 sampai dengan 1997, hasil penelitian Chang, Chand, Das, dan Li (2004) menunjukkan bahwa setelah adanya national health insurance (NHI), rata-rata tingkat efisien rumah sakit distrik di Taiwan menurun. Sedangkan hasil analisis data panel dari tahun 1990 sampai dengan tahun 2001 yang dilakukan oleh Hung dan Chang (2008) menunjukkan bahwa semakin luasnya cakupan asuransi kesehatan (khususnya untuk manusia usia lanjut dan penanganan yang lebih untuk berbagai tipe penyakit yang berat), serta meningkatnya kompetisi (karena berkembangnya teknologi dan semakin panjangnya lama rawat inap) 
merupakan pemicu dari meningkatnya biaya rumah sakit yang langsung terasa akibat semakin luasnya penerapan NHI di Taiwan.

Ernst dan Szczesny (2005) juga meneliti mengenai pengaruh dari adanya asuransi kesehatan nasional. Namun ruang lingkup penelitian Ernst dan Szczesny terbatas pada bagaimana proses pembelajaran (learning process) di ruang bedah rumah sakit (dengan cakupan rumah sakit di Jerman sebagai sampel) mempengaruhi akuntansi biaya rumah sakit dalam era diagnosis related group - DRG (sistem penentuan biaya dalam sistem asuransi kesehatan nasional di Jerman). Hasil penelitian Ernst dan Szczesny menunjukkan bahwa lama waktu prosedur (procedure time) pembedahan merupakan pemicu biaya (cost driver) yang tepat dalam biaya operasi bedah, dan efek pembelajaran (learning effect) mempengaruhi waktu prosedur (procedure time) pembedahan.

Lehtonen (2007), telah melakukan kajian literatur dengan periode yang sangat panjang, yaitu dari tahun 1983 sampai dengan tahun 2005, untuk mengetahui mekanisme penerapan DRG dan case-mix accounting seperti apa yang telah sukses diterapkan di rumah sakit. Hasil penelitiannya menunjukkan bahwa penerapan DRG dan case-mix accounting di suatu rumah sakit akan sukses jika pihak manajemen rumah sakit mengikutsertakan tenaga medis (seperti dokter) dalam perumusan sistem kontrol manajemen. Sistem ini juga akan berhasil jika implementasi diterapkan secara bertahap dan ada tekanan yang intensif dari manajemen untuk menerapkan sistem tersebut.

\section{Cost Recovery}

Pelaksanaan pelayanan bagi masyarakat tidak mampu di rumah sakit memperoleh subsidi dari pemerintah. Namun laporan-laporan yang diterima Departemen Kesehatan, menunjukkan bahwa sebagian rumah sakit tersebut mengalami defisit ${ }^{5}$. Berdasarkan penelitian Bambang (2009) yang menguji mengenai impas biaya rumah sakit pemerintah, mengatakan bahwa hanya $14,7 \%$ rumah sakit yang dapat mencapai impas biaya (cost recovery) sedangkan $85.3 \%$ tidak berhasil mencapai impas biaya. Penelitian tersebut juga mengatakan bahwa pendapatan total rumah sakit pemerintah pada umumnya lebih rendah dibanding pengeluaran total. Menurut Thabrany dkk (1995) dalam Bambang (2009) pelayanan kesehatan dilepaskan sepenuhnya pada mekanisme pasar dengan memberikan sesuai kemampuan dan kemauan konsumen untuk membayar, akibatnya masyarakat mampu yang lebih banyak menikmati fasilitas pelayanan. Penelitian Bambang (2009) membuktikan bahwa pendapatan RSU pemerintah dari subsidi pemerintah untuk membayar produk/jasa yang dikonsumsi masyarakat miskin yang berlaku saat ini tidak cukup untuk menutup pengeluaran biaya rumah sakit, sehingga impas biaya (cost recovery) rumah sakit umum tidak tercapai. Penelitian tersebut mengatakan bahwa subsidi pemerintah ternyata hanya dapat menutup $5 \%$ dari defisit yang terjadi, sehingga wajar jika sebagian besar rumah sakit tidak mampu mencapai impas biaya. Penelitian Bambang (2009) menggunakan teori ekonomi neoklasik yang ternyata tidak dapat diterapkan secara apa adanya dalam menganilisi rumah sakit umum milik pemerintah. Faktor-faktor yang selama ini oleh teori ekonomi neoklasik dianggap berpengaruh besar terhadap volume penjualan produk/jasa, ternyata tidak memiliki korelasi yang bermakna dengan volume penjualan, seperti yaitu harga, baik harga produk/jasa rumah sakit maupun harga produk/jasa yang berkaitan tidak dapat berpengaruh terhadap volume penjualan produk/jasa rumah sakit. Penelitian ini menggunakan data dari rumah sakit umum daerah yang memiliki perbedaan karakteristik dengan rumah sakit swasta diperkotaan seperti fasilitas, demand atas rumah sakit, karakteristik penduduk dan tingkat pendapatan penduduk. Seperti yang dikatakan oleh Feldstein (1999), keluarga yang memiliki pendapatan lebih tinggi akan 
lebih banyak pengeluarannya untuk pelayanan medis. Berbeda dengan penelitian Muttaqien AlMaidin dkk (2013) mengatakan bahwa penetapan tarif dengan menggunakan Relative Value Unit (RVU) untuk tindakan operasi sudah sesuai diterapkan untuk masyarakat miskin penerima bantuan melalui program Jamkesmas di RSUD Kota Batam kepulauan Riau, namun penelitian tersebut menyebutkan perlunya pengkajian dan penyesuaian terhadap beberapa tarif yang diberlakuan dalam sistem INA-CBG.

Selain itu, penelitian Budiarto dan Sugiarto (2012) memberikan bukti bahwa biaya klaim rawat inap menurut INA-CBGs untuk penyakit katastropik di kelas A lebih tinggi dibandingkan dengan semua rumah sakit. Pada penelitian tersebut juga disebutkan bahwa biaya klaim INACBGs lebih besar $14.39 \%$ dibandingkan dengan biaya menurut tarif rumah sakit baik rumah sakit kelas A,B dan RS Khusus.

Komponen biaya paling banyak dikeluarkan dari biaya klaim adalah biaya obat (11-31\%), biaya akomodasi (7-26\%), tindakan ruangan (8-32\%) dan pemeriksaan laboratorium (6-19\%) pada penelitian Budiarto dan Sugiarto (2012).

\section{METODE PENELITIAN}

Penelitian ini menggunakan data primer dan data sekunder. Data primer diperoleh melalui wawancara kepada beberapa pejabat rumah sakit. Hasil wawancara akan digunakan untuk menentukan nilai cost driver untuk pembebanan biaya tidak langsung. Data sekunder menggunakan Laporan Bulanan, Laporan Pemakaian biaya langsung dan tidak langsung, data investasi dan lainnya. Sampel populasi semua pasien JKN rawat jalan yang berobat di Poli Bagian dari bulan Januari 2014 - Oktober 2014.

\section{Kerangka Penelitian}

Kerangka penelitian dalam menganalisis cost recovery rate dari pasien JKN dalam penelitian ini, adalah sebagai berikut:

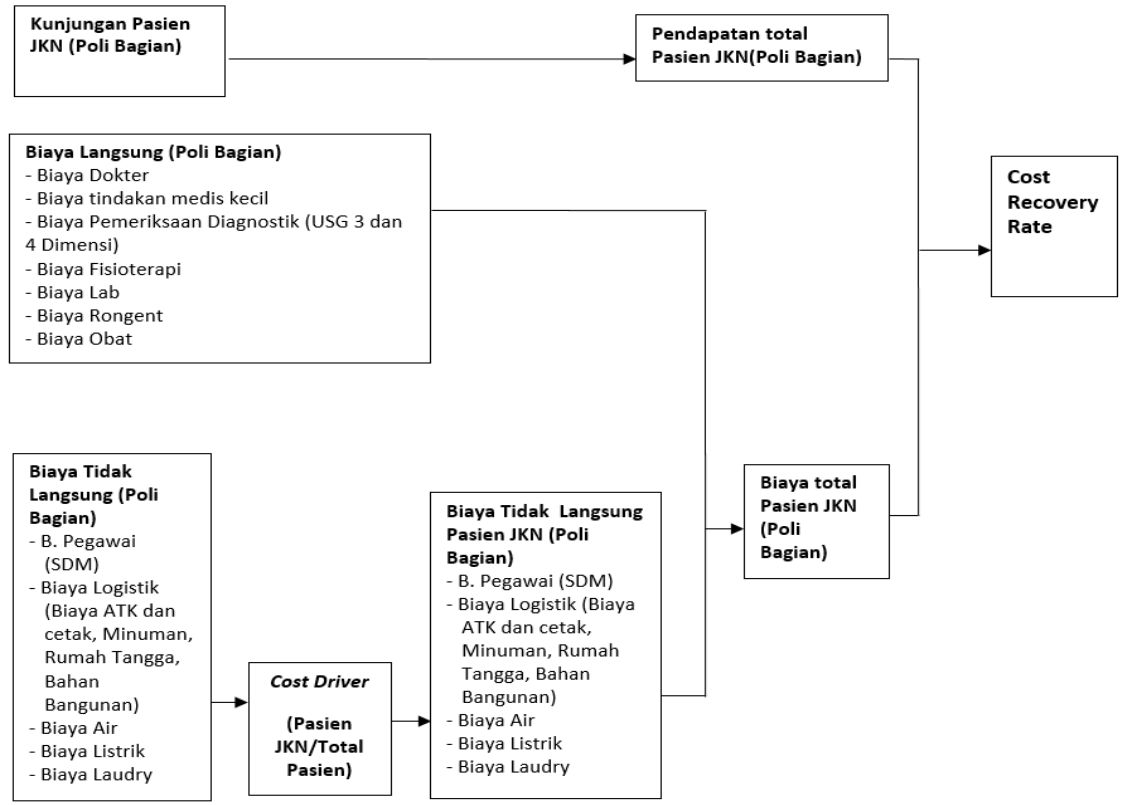

Gambar 1. Kerangka Penelitian 


\section{HASIL DAN PEMBAHASAN}

Berikut ini adalah hasil statistik deskriptif yang dijelaskan pada tabel 1 dibawah ini:

Tabel 1

Statistik Deskriptif

\begin{tabular}{|c|r|r|r|}
\hline & Minimum & Maximum & \multicolumn{1}{c|}{ Rata-Rata } \\
\hline Pasien MR & 1.902 & 2.828 & 2.233 \\
\hline Pasien JKN & 939 & 2.142 & 1.299 \\
\hline Pasien non JKN & 686 & 1.167 & 935 \\
\hline Pendapatan & 159.929 .095 & 425.833 .300 & 245.515 .824 \\
\hline Biaya Langsung JKN & 139.516 .424 & 370.246 .750 & 215.556 .578 \\
\hline Profit langsung & 10.950 .649 & 55.586 .550 & 29.959 .246 \\
\hline Logistik & 1.473 .026 & 2.894 .773 & 2.177 .842 \\
\hline Biaya SDM & 47.213 .319 & 47.213 .319 & 47.213 .319 \\
\hline Biaya Listrik & 2.405 .390 & 3.747 .446 & 2.968 .997 \\
\hline Biaya Air & 64.838 & 101.665 & 77.891 \\
\hline Biaya Loundry & 1.725 .000 & 2.100 .000 & 1.891 .667 \\
\hline
\end{tabular}

Berdasarkan data statistik deskriptif pasien JKN lebih banyak dibandingkan pasien Non-JKN, dengan rata-rata pasien JKN adalah 1.299 per bulan, sedangkan pasien Non-JKN hanya sebesar 935 per bulan. Pendapatan rata-rata rumah sakit atas pelayanan JKN setiap bulannya sebesar Rp245.515.824. Keuntungan rata-rata berdasarkan hitungan dari rumah sakit adalah sebesar Rp29.959.246 atau sebesar 12\% dari pendapatan. Dan biaya SDM merupakan komponen biaya tidak langsung terbesar dibandingkan komponen biaya tidak langsung lainnya.

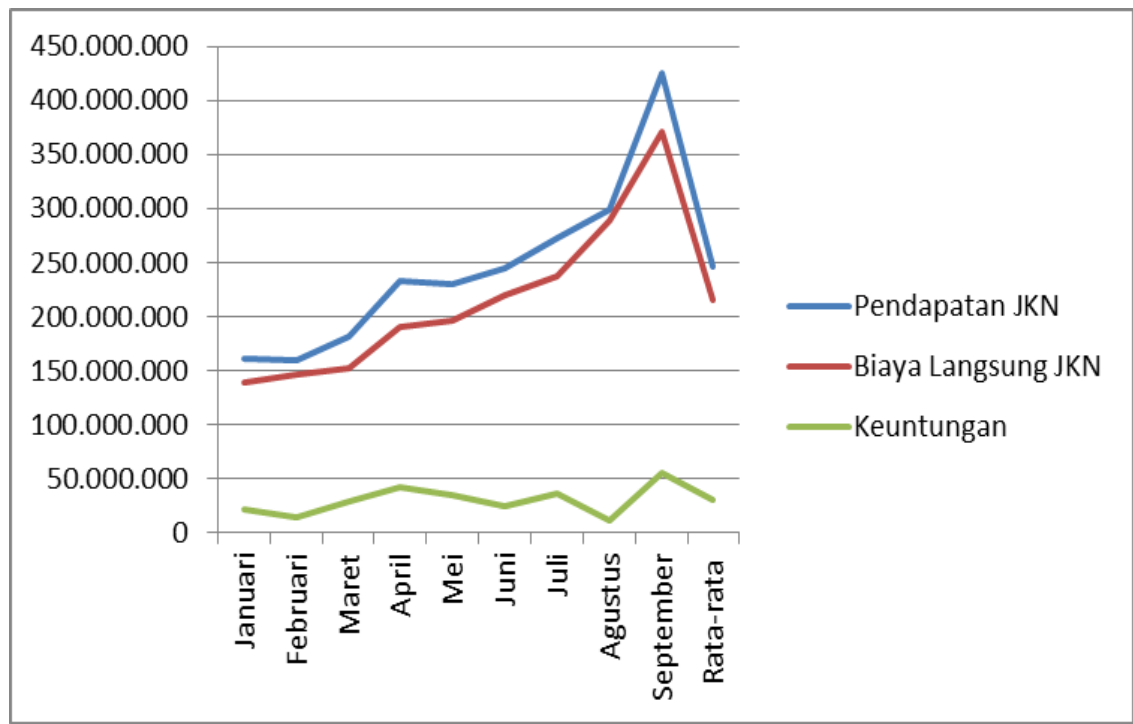

Gambar Pendapatan, biaya dan keuntungan atas pelayanan JKN berdasarkan perhitungan rumah sakit $\mathrm{XYZ}$ 
Sedangkan presentase keuntungan akan ditampilkan pada tabel 2 dibawah ini:

Tabel 2. Persentase keuntungan

\begin{tabular}{|l|r|r|r|r|r|r|}
\hline \multicolumn{1}{|c|}{ BULAN } & Pendapatan & $\begin{array}{c}\text { Biaya } \\
\text { Langsung }\end{array}$ & $\begin{array}{c}\text { Contributi } \\
\text { on Margin }\end{array}$ & $\begin{array}{c}\text { Biaya } \\
\text { Tidak } \\
\text { Langsung }\end{array}$ & $\begin{array}{c}\text { Keuntu- } \\
\text { ngan }\end{array}$ & $\begin{array}{c}\text { \% } \\
\text { Keun- } \\
\text { tungan }\end{array}$ \\
\hline Januari & 161.366 .397 & 132.473 .924 & 28.892 .473 & 31.198 .749 & $(\mathbf{2 . 3 0 6 . 2 7 6 )}$ & $-1 \%$ \\
\hline Februari & 159.929 .095 & 138.919 .323 & 21.009 .772 & 31.133 .964 & $(10.124 .192)$ & $-6 \%$ \\
\hline Maret & 181.391 .293 & 143.993 .921 & 37.397 .372 & 31.099 .862 & 6.297 .510 & $3 \%$ \\
\hline April & 233.232 .169 & 181.694 .728 & 51.537 .441 & 31.460 .522 & 20.076 .919 & $9 \%$ \\
\hline Mei & 230.797 .711 & 176.533 .185 & 54.264 .526 & 31.347 .747 & 22.916 .779 & $10 \%$ \\
\hline Juni & 244.394 .825 & 186.492 .438 & 57.902 .387 & 31.165 .747 & 26.736 .640 & $11 \%$ \\
\hline Juli & 273.208 .054 & 205.341 .008 & 67.867 .046 & 32.249 .923 & 35.617 .123 & $13 \%$ \\
\hline Agustus & 299.489 .571 & 249.688 .922 & 49.800 .649 & 32.494 .993 & 17.305 .656 & $6 \%$ \\
\hline September & 425.833 .300 & 316.696 .750 & 109.136 .550 & 32.155 .078 & 76.981 .472 & $18 \%$ \\
\hline Total & $\mathbf{2 . 2 0 9 . 6 4 2 . 4 1 5}$ & $\mathbf{1 . 7 3 1 . 8 3 4 . 1 9 9}$ & $\mathbf{4 7 7 . 8 0 8 . 2 1 6}$ & $\mathbf{2 8 4 . 3 0 6 . 5 8 5}$ & $\mathbf{1 9 3 . 5 0 1 . 6 3 1}$ & $\mathbf{9 \%}$ \\
\hline
\end{tabular}

Biaya langsung dari pasien JKN adalah biaya-biaya yang dapat ditelusuri secara langsung terhadap pelayanan pasien JKN yaitu Biaya Administrasi, Biaya Dokter, Biaya tindakan medis kecil, Biaya Pemeriksaan Diagnostik (USG 3 dan 4 Dimensi), Biaya Fisioterapi, Biaya Laboratorium, Biaya Rongent dan Biaya Obat sesuai penyakit dari pasien JKN. Dalam komponen biaya langsung tersebut rumah sakit membebankan biaya administrasi yang merupakan komponen biaya tidak langsung sebesar Rp2.500 per pasien sampai dengan April 2014, setelahnya meningkat menjadi Rp25.00o.

Berdasarkan rincian pendapatan, biaya dan keuntungan atas pelayanan JKN berdasarkan perhitungan rumah sakit XYZ (lihat lampiran), rata-rata keuntungan yang diperoleh sebesar $12 \%$ dari rata-rata sampel Januari sampai September 2014. Dengan keuntungan terendah sebesar $4 \%$ pada bulan agustus 2014 .

Berikut ditampilkan tabel cost recovery rate pelayanan pasien JKN di bawah ini:

Tabel 3. Cost recovery rate Pelayanan Pasien JKN

\begin{tabular}{|l|r|r|c|}
\hline \multicolumn{1}{|c|}{ BULAN } & $\begin{array}{c}\text { Pendapatan } \\
\text { JKN }\end{array}$ & TOTAL COST & Cost Recovery Rate \\
\hline Januari & 161.366 .397 & 163.672 .673 & $101 \%$ \\
\hline Februari & 159.929 .095 & 170.053 .287 & $106 \%$ \\
\hline Maret & 181.391 .293 & 175.093 .783 & $97 \%$ \\
\hline April & 233.232 .169 & 213.155 .250 & $91 \%$ \\
\hline Mei & 230.797 .711 & 207.880 .932 & $90 \%$ \\
\hline Juni & 244.394 .825 & 217.658 .185 & $89 \%$ \\
\hline Juli & 273.208 .054 & 237.590 .931 & $87 \%$ \\
\hline Agustus & 299.489 .571 & 282.183 .915 & $94 \%$ \\
\hline September & 425.833 .300 & 348.851 .828 & $82 \%$ \\
\hline \multicolumn{1}{|c|}{ Rata-rata } & 245.515 .824 & 224.015 .643 & $93 \%$ \\
\hline
\end{tabular}


Berdasarkan analisis cost recovery rate biaya yang dihitung tidak hanya biaya langsung, namun harus mencakup biaya tidak langsung. Biaya tidak langsung yaitu biaya yang tidak dapat ditelusuri secara langsung dari pelayanan pasien JKN namun berpengaruh terhadap pelayanan fasilitas JKN. Biaya tidak langsung terdiri atas biaya gaji, biaya logistik, biaya air dan biaya listrik. Biaya penyusutan tidak dimasukan dalam penelitian ini, karena keterbatasan data yang bisa diperoleh.

Penelitian ini menelusuri rincian seluruh biaya yang terjadi termasuk biaya langsung dan tidak langsung serta proses pengalokasian yang terjadi untuk biaya overhead. Data biaya tidak langsung yang diperoleh merupakan biaya untuk pelayanan JKN dan Non JKN maka untuk mengetahui biaya tidak langsung untuk pasien JKN perlu dilakukan alokasi anggaran biaya tidak langsung untuk pasien JKN. Alokasi dilakukan dengan menggunakan jumlah pasien sebagai cost driver (pemicu).

Berikut adalah dasar alokasi yang digunakan untuk biaya tidak langsung:

$\underline{\text { Pasien JKN } \quad=\underline{11.687}=58 \%}$

Total Pasien (JKN dan Non JKN) $\quad 20.100$

Dasar alokasi sebesar 58\% akan digunakan untuk menentukan besarnya biaya tidak langsung untuk pelayanan fasilitas JKN. Besaran biaya tidak langsung untuk pasien JKN terdiri dari biaya logistik, biaya SDM, biaya listrik, biaya air, biaya laundry. Setelah biaya administrasi dikeluarkan dalam komponen biaya langsung dan dilakukan perhitungan ulang komponen biaya tidak langsung maka keuntungan atas pelayanan pasien JKN rata-rata sebesar 9\% (lihat lampiran).

Dari hasil penelitian menemukan bahwa biaya yang dikeluarkan oleh rumah sakit baik biaya tetap maupun tidak tetap tertutup oleh pendapatan pelayanan pasien JKN dari tarif INA CBG's. Dengan perhitungan angka riil pendapatan dikurangi total biaya langsung dan tidak langsung maka keuntungan yang diperoleh rumah sakit adalah sebesar 9\%.

Berdasarkan data primer, biaya yang dikeluarkan oleh rumah sakit merupakan biaya pelayanan minimum yang telah menyesuaikan dengan tarif INA CBG's. Dengan pelayanan minimum, rata-rata cost recovery rate adalah sebesar 93\%, dan keuntungan berdasarkan data riil rata-rata sebesar $9 \%$.

\section{SIMPULAN}

Penelitian ini menemukan bahwa cost recovery rate untuk pasien JKN dalam pelayanan rawat jalan di rumah sakit XYZ rata-rata sebesar 93\% untuk sampel 9 bulan, dengan keuntungan yang diperoleh rata-rata sebesar 9\%, dapat dikatakan bahwa keuntungan yang diperoleh rumah sakit sangat minim. Keuntungan tersebut belum termasuk perhitungan beban depresiasi yang merupakan keterbatasan dalam penelitian ini. Namun mengingat ini merupakan program pemerintah untuk membantu masyarakat miskin maka keuntungan yang diperoleh memang tidak maksimal.

Apabila perhitungan didasarkan pada biaya langsung pasien JKN saja secara keseluruhan contribution margin rumah sakit pada tingkat positif surplus. Apabila perhitungan memasukan biaya overhead atau biaya tidak langsung maka pada awal-awal penerapan kebijakan JKN yaitu bulan Januari dan Februari rumah sakit mengalami defisit. Namun setelah bulan Maret sampai dengan bulan September 2014 rumah sakit selalu mengalami keuntungan. Selisih antara tarif JKN dan cost of recovery rate pada bulan Januari dan Februari menunjukan hasil negatif artinya rumah sakit mengalami kerugian, sedangkan pada bulan Maret sampai dengan September mengalami hasil positif atau rumah sakit memperoleh keuntungan. Sehingga berdasarkan cost 
recovery rate dari data riil, tarif JKN secara nyata masih memberikan keuntungan bagi rumah sakit. Dengan kata lain, pendapatan dari pelayanan pasien JKN rawat jalan di rumah sakit XYZ dapat menutupi biaya yang dikeluarkan untuk pelayanan tersebut.

Penelitian ini memiliki beberapa kelemahan yaitu data yang dijadikan analisis hanya 9 bulan yaitu bulan Januari sampai dengan September 2014, sehingga tambahan sampel bulan akan semakin mempertajam penelitian ini. Selain itu, biaya depresiasi tidak dimasukan dalam perhitungan, sehingga bisa jadi biaya ini akan menurunkan keuntungan secara signifikan. Penelitian selanjutnya dapat menambah jumlah bulan sebagai sampel penelitian, memasukan komponen depresiasi dan dapat menggunakan rumah sakit pemerintah sebagai pembanding dari hasil cost recovery rate atas penerapan implemantasi pasien JKN di rumah sakit serta untuk mempertajam hasil penelitian dapat ditambahkan dengan penelitian kualitatif.

\section{PUSTAKA ACUAN}

BPJS. 2014. fee-for-service-vs-ina-cbgs-mana-yang-lebih-menguntungkan.

http://bpjs-kesehatan.go.id/berita-183-fee-for-service-vs-ina-cbgs-mana-yang-lebihmenguntungkan.html. Diakses 22 Agustus 2014

BPJS-Kesehatan.go.id. 2014 http://bpjs-kesehatan.go.id/berita-168-39-item-tarif-ina-cbgs-sudah-direvisikemkes.html. akses 22 Agustus 2014

Buletin BUK, Direktorat Jendral Bina Upaya Kesehatan Kementrian Kesehatan RI. Edisi Mei 2013

Chang, Hsihui., Chang, Wen-Jing., Das, Somnath., dan Li, Shu-Hsing (2004). Health care regulation and the operating efficiency of hospitals: Evidence from Taiwan. Journal of Accounting and Public Policy 23, 483-510.

Departemen Kesehatan R.I., Keputusan Menteri Kesehatan No. 582/Menkes/SK/VI/2014 tentang Pola Tarif Rumah Sakit Pemerintah, 2014.

Ernst, Christian., dan Szczesny, Andrea (2005). Cost Accounting Implications of Surgical Learning in The DRG Era - Data Evidence from a German Hospital, Schmalenbach Business Review, vol. 57, April 2005, 127-166.

Feldstein, PJ. Healthcare economics. Sam Fransisco; Delmar Publisher, 1999.

Hartono. Bambang (2009) Analisis pencapaian impas-biaya rumah sakit umum pemerintah dalam rangka pelayanan bagi masyarakat miskin: studi Kasus Jawa Tengah. Buletin Penelitian Kesehatan, Vol. 37, No. 1, 2009: 1-11.

Hung, Jung-Hua., dan Chang, Li (2008). Has cost containment after the National Health Insurance system been successful? Determinants of Taiwan hospital costs. Health Policy $85 \cdot 321-335$.

Nasional Sindo New.Com.2014 http://nasional.sindonews.com/read/830542/15/tarif-ina-cbgs-ganggu-pelayanan-rs. Diakses 22 Agustus 2014

Lehtonen, Taru (2007). DRG-based prospective pricing and case-mix accounting - Exploring the mechanisms of successful implementation. Management Accounting Research 18, 367-395.

Kompas.com.2013. Hari Ini Presiden Luncurkan BPJS. http://nasional.kompas.com/read/2013/12/31/o845001/Hari.Ini.Presiden.Luncurkan.BPJS diakses 22 Agustus 2014. 
Muttaqien Al-Maidin. Achmad R., Noor. Noer Bahry, Pasinringi. Syahrir A. (2013). Perbandingan Tarif Tindakan Operasi BerdasarkanRelative Value Unit (RVU), Indonesia Case Based Groups(Ina-Cbg's) Dan Tarif Kolegium

Peraturan BPJS no 1 Tahun 2014 tentang Penyelenggaraan Jaminan Kesehatan.

Rocmad A, et al. Evaluasi Rumah Sakit umum swadana RSU Daerah sebagai Unit sosial Ekonomi. Jakarta. Ditjen Pelayan Medik WHO. 1999.

Thabrany, H. Health Insurance and demand for medicak care in Indonesia. Disertasi (Doktor). Berkeley: University of California; 1995

Wasis Budiarto Dan Mugeni Sugiharto. 2013. Biaya Klaim Ina Cbgs Dan Biaya Riil Penyakit KatastropikRawat Inap Peserta Jamkesmas Di Rumah SakitStudi Di 10 Rumah Sakit Milik Kementerian KesehatanJanuari-Maret 2012. Buletin Penelitian Sistem Kesehatan Vol. 16 No. 1 Januari 2013: 58-65. 